\title{
National Surveillance Programme for Aquatic Animal Diseases - a stepping stone for establishing disease governance system in India
}

\author{
Neeraj Sood, Pravata K. Pradhan, T. Raja Swaminathan, Gaurav Rathore, J. K. Jena and \\ Kuldeep K. Lal*
}

The main driver for National Surveillance Programme for Aquatic Animal Diseases (NSPAAD) in India is the threat of diseases to the growth of aquaculture. Keeping this in consideration, the Department of Fisheries (DoF), Government of India (GoI) is implementing NSPAAD involving 31 collaborating centres in 19 states, and this programme is being coordinated by ICAR-NBFGR, Lucknow. The programme has been successful in developing a network of aquatic animal health laboratories; diagnostic capability for detection of OIE/NACA-listed and emerging pathogens; mechanism for first time confirmation of new diseases; sending alerts/advisories to stakeholders; and providing scientific advice to the farmers. NSPAAD has helped in strengthening passive disease surveillance, which is evident by detection of seven new pathogens. It has enabled DoF in better understanding of disease situation in the country, and meeting international disease reporting obligations. Currently, DoF is contemplating to further strengthen the disease surveillance programme.

Keywords: Aquatic animals, disease surveillance, governance system, national programme.

EARLY recognition of signs of disease outbreak, and rapid and accurate diagnosis of its infectious aetiology are important for effective disease management. A key aspect of preventing the spread of disease is credible reporting at the national and international levels. Regional and global mechanisms are in place for such obligatory reporting of aquatic animal diseases by the nations to international organizations such as the Network of Aquaculture Centres in Asia-Pacific (NACA) and World Organisation for Animal Health (OIE). The timely reporting helps countries at risk to undertake preventive and mitigation measures to safeguard their aquatic animal populations. The prevailing situation due to the COVID-19 pandemic provides one of the best examples to understand this fact. Notwithstanding the risks to human health from human or zoonotic pathogens, diseases of farm animals reduce the availability of an important source of nutrition besides causing economic loss to the fish farmers, majority of whom are small-scale farmers. Aquatic animal disease surveillance is important for timely warning of diseases, planning and monitoring of disease control programmes, provision of sound aquatic animal health advice to far-

The authors are in the ICAR-National Bureau of Fish Genetic Resources, Canal Ring Road, P.O. Dilkusha, Lucknow 226 002, India; J. K. Jena is in the Indian Council of Agricultural Research, Krishi Anusandhan Bhawan-II, Pusa, New Delhi 110 002, India.

*For correspondence. (e-mail: kuldeepklal@gmail.com) mers and international disease reporting obligations. Prevention of spread of diseases from one state to another is crucial, as outlined in The Prevention and Control of Infectious and Contagious Diseases in Animals Act, 2009 and subsequent amendment in 2014. The Department of Animal Husbandry, Dairying and Fisheries, Ministry of Agriculture, Government of India envisioned the National Surveillance Programme for Aquatic Animal Diseases (NSPAAD) to fulfil the spirit of the legislative Act and international reporting obligations. These initiatives taken by India safeguard the interest of its aquafarming community and the associated income.

Aquaculture in Asia, including India has shown a growth of over $7 \%$ during the last two decades and this is one of the fastest growing food sectors. The transboundary movement of aquatic animals has significantly contributed to the growth; however, it has also increased the risk of spread of new and emerging diseases to new regions. Some examples include spread of Aphanomyces invadans due to movement of live fish from epizootic ulcerative syndrome-affected countries; spring viraemia of carp virus due to movement of ornamental fish; rapid spread of white spot syndrome virus throughout South and Southeast Asia due to irresponsible movement of post-larvae and broodstock between countries, and introduction of infectious myonecrosis virus from Brazil to Indonesia ${ }^{1}$. Recently, it has been suggested that tilapia lake virus could have spread to 40 countries, including India, from three infected tilapia hatcheries in Thailand ${ }^{2}$. 


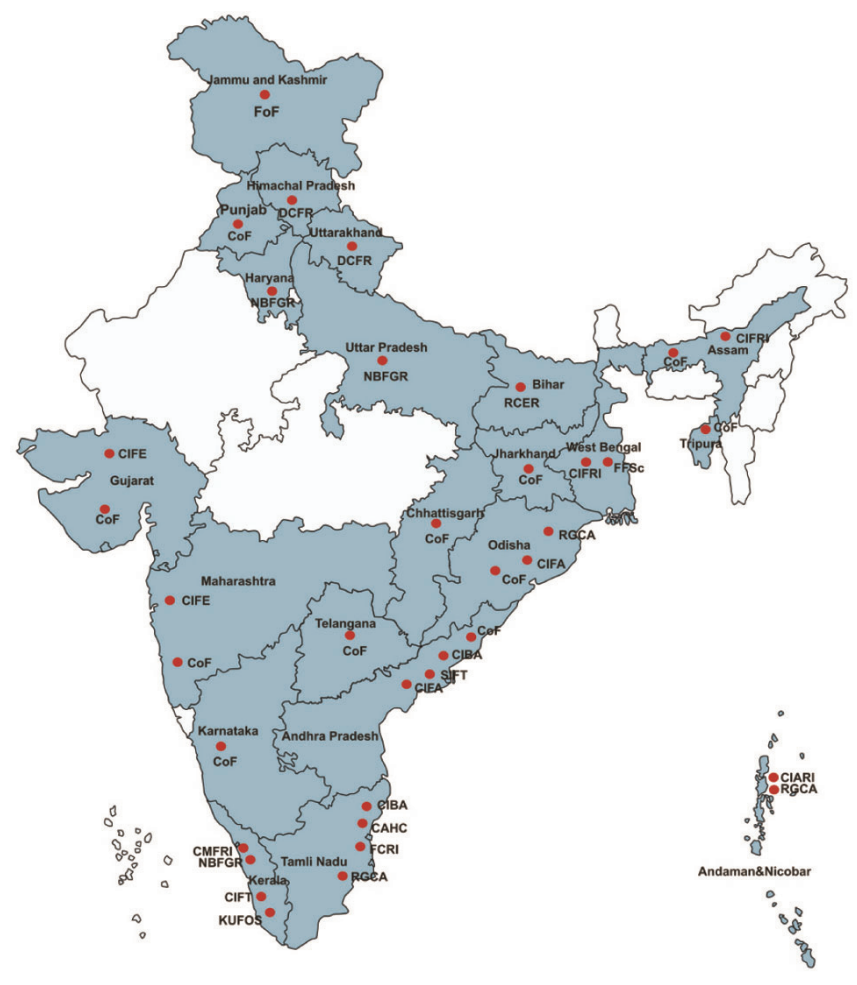

Figure 1. States and Union Territories covered under NSPAAD and collaborating centres responsible for implementing surveillance in each state.

The introduction of diseases is associated with huge production losses. In India, annual losses due to shrimp diseases were estimated to be approximately Rs 1022.1 crores during 2006-2008, when shrimp production in the country was 144,347 tonnes in 2006-2007 and 106,165 tonnes in 2007-2008 (ref. 3) as against the present production of about 800,000 tonnes (ref. 4).

\section{Implementation of NSPAAD}

India is a vast country with state administrative structure, and divergent levels of capabilities and fisheries priorities. Therefore, establishing a coordinated surveillance programme remained a challenge and there was no working model to follow from other countries. The National Surveillance Programme for Aquatic Animal Diseases (NSPAAD) of India made its own example. One of the driving factors has been the quick and close harmony of the policy strength and research expertise. This has helped to develop a prototype of an aquatic animal disease surveillance programme, which can be institutionalized in future. As a result, with funding through the National Fisheries Development Board, (NFDB), Hyderabad, NSPAAD was implemented with the ICARNational Bureau of Fish Genetic Resources (NBFGR), Lucknow as a lead institute. The success has become visible within a short span of six years and the programme, initiated in 14 States, has been expanded to cover 19 States and 2 Union Territories (UTs) with 31 collaborating centres (Figure 1). NSPAAD has assisted the Department of Fisheries (DoF), Ministry of Fisheries, Animal Husbandry and Dairying, Govt of India (GoI) in a better understanding of disease situation in aquatic animals and has reached the stage to conclusively report presence or absence of diseases in the country. The programme has been helping in providing evidence-based inputs to DoF regarding aquatic animal health issues, introduction of exotics, and trade and science-based inputs to queries from the trading countries.

The foremost accomplishment which laid the foundation of NSPAAD was the diagnostic manual containing internationally agreed protocols for diagnosis of diseases of concern ${ }^{5}$ and procuring positive nucleic acid controls from the OIE reference and other international laboratories. The positive controls procured by the lead centre were propagated in the laboratory and distributed to all the centres in the network. Simultaneously, the diagnostic capability for OIE-listed and emerging diseases was also developed. In the beginning, investigators involved in the project were sensitized about surveillance and its underpinning science. In order to update the knowledge of the project investigators on disease surveillance and different aspects of aquatic animal health, several international 
events and training programmes on aquatic animal epidemiology were organized and supported by internationally acclaimed experts. The multipronged strategy has established trained manpower and a network of technically competent laboratories, validated under NSPAAD. This serves as a background model for the enhancement and establishment of high-throughput laboratories in the states under the newly launched Prime Minister's Matshya Sampada Yojana (PMMSY), GoI.

\section{Impacts of NSPAAD}

NSPAAD aimed for a long-term objective of strengthening the passive surveillance system in the country, which is the most accepted form of surveillance globally and even for livestock diseases. Till date, over 26,000 stakeholders have benefitted through more than 500 awareness programmes organized under the NSPAAD. The focus of such programmes has been to create awareness about major diseases, their management, reporting of major incidents of mortality and the method of transporting diseased fish samples to nearby laboratories. Besides, over 65 training programmes for about 1600 officers of the State Fisheries Departments and research scholars have been organized to strengthen their diagnostic capability. Further, about 1800 disease cases have been investigated by different collaborating centres and scientific advice provided to the farmers to manage the diseases in order to minimize losses due to aquatic animal diseases. Importantly, over the years, there has been an increase in disease reporting by the farmers. The strengthening of passive disease surveillance is also evident by the diagnosis of seven new diseases for the first time from the country. These include goldfish haematopoietic necrosis disease due to cyprinid herpesvirus-2 (ref. 6); koi sleepy diseases due to carp edema virus ${ }^{7}$; hepatopancreatic microsporidiosis due to Enterocytozoon hepatopenaei ${ }^{8}$; infectious myonecrosis due to infectious myonecrosis virus ${ }^{9}$, epitheliocystis due to Candidatus Actinochlamydia pangasiae sp. nov. ${ }^{10}$; tilapia lake virus disease due to tilapia lake virus ${ }^{11}$ and infection with red sea bream iridovirus $^{12}$.

NSPAAD also implemented limited-level active surveillance, which is not a routine method globally in any sector. However, in India, it has a unique purpose as this programme started from scratch, without any groundlevel information collection system, similar to veterinary hospitals in animal husbandry. There was a necessity to quickly validate the techniques and capacity building of researchers in carrying out disease surveillance. This has also helped in improving disease reporting by small-scale farmers, who are otherwise hesitant to inform about disease occurrence in their farms. There was also a compelling need to understand that the strategies envisioned for surveillance can capture the disease occurrence. The active surveillance data show that four major pathogens of finfish and two of shrimps have not been detected in India, and provide transparent scientific evidence for the same. These are koi herpesvirus, spring viremia of carp virus, infectious pancreatic necrosis virus and Viral haemorrhagic septicemia virus in finfish, and yellow head virus and taura syndrome virus in shrimp. All the first reports of new diseases were validated using internationally accepted methods, besides fulfiling reporting obligations to OIE, wherever applicable, and these have also been published in peer-reviewed high-impact journals.

Targeted active surveillance was implemented in case of some new diseases like acute hepatopancreatic necrosis disease (AHPND), hepatopancreatic microsporidiosis and infectious myonecrosis to know their spatial spread. In some of the emergent situations, rapid response teams were constituted which surveyed and analysed the large number of samples from farms. This process was employed for most of the newly diagnosed diseases. Interestingly, a different emergent scenario developed during 2012 and 2013, when global shrimp production crashed due to losses from the spread of AHPND, and its presence was speculated in India too. The response from this programme in the form of targeted active surveillance helped dispel the rumours of AHPND (an OIE-listed disease) in the country and infuse confidence in its farmers/importers. India was found to be free from Vibrio parahemolyticus AHPND strain. The export of shrimps remained vibrant, with increase in earning by more than $50 \%$ higher in terms of value (over previous years), with only $12 \%$ increase in production. The confidence restored in farming and trading communities is also reflected in the emergence of Southeast Asia as a new and major importer block. This could be considered as one example to understand the tangible benefits from investments in building surveillance capacity, which can be accrued at the time of need.

The strong country-wide network of aquatic animal health laboratories, mechanisms for rapid and accurate confirmation of exotic and emerging diseases, and an early warning system through alerts following first-time reports of emerging and exotic diseases which are established, will serve as a background to take surveillance to the next level; possibly an institutionalized system in the future. The diagnosis of disease cases and scientific advice to the farmers are likely to help in reducing production losses. Documenting such changes in production loss as a result of diagnosis and early alerts, their social and economic impacts can be an important area of research in the future. The national database on aquatic animal diseases established during the programme is a long-term asset for enrichment with data on disease occurrence in relation to the environment, husbandry practices in a spatial and temporal scale, and thereby enabling the nation to acquire a platform for compatibility with upcoming analytical technologies for prediction of diseases. The transparent 
reporting of aquatic animal diseases has enhanced the credibility of India with the international organizations. The programme contributed significantly to the science with publication of over 50 articles in peerreviewed journals with high impact factor. Implementing surveillance programme in a country like India can serve as a model for other countries or groups of countries in Asia, which produce $90 \%$ of global aquaculture and also jointly carry the risk of diseases. India's aquatic disease surveillance programme has been highlighted in the QAAD report for Asia and Pacific region (October to December 2016), published jointly by NACA and OIE (1494556312_quarterly-aquatic-animal-disease-reportoctober-december-2016.pdf). India's surveillance programme was also invited for a keynote presentation during the second International Conference on Aquatic Animal Epidemiology (AquaEpi II) held in Thailand in November 2019. Importantly, India will host AquaEpi III in New Delhi during November 2022. Some of the major challenges for effective implementation of the surveillance programme, include under-reporting of diseases by the farmers in spite of awareness programmes. It is envisaged that involvement of officers of State Fisheries Departments and their linkages with farmers at the grassroot level can help improve disease reporting. Currently, the number of laboratories carrying out disease investigations are limited. Therefore, strengthening of collection and transportation of disease samples to the nearest laboratory and timely sharing of the results of disease investigation can help in increasing involvement of farmers in the programme. Many a times, there is delay in the diagnosis of new and emerging diseases resulting in their spread. Therefore it becomes difficult to eradicate/control the disease. Thus, enhancing the involvement of farmers and officers of State Fisheries Departments will help in early diagnosis of new and emerging diseases, thereby helping in control measures to minimize their spread and eradication. Furthermore, tracking the source of infection in case of new diseases is a major challenge which can be solved by tracking the movement of aquaculture inputs, including seeds. Moreover, at present, there is scarcity of information regarding economic losses due to diseases. The collection of information regarding disease loss can help in prioritization of diseases for undertaking control measures as well as research efforts.

\section{Future perspectives toward an institutionalized surveillance system}

The future format of NSPAAD will set the process for its institutionalization to mitigate the threat from emerging diseases in aquaculture. This sector is expected to undergo a paradigm shift in terms of intensification, diversification, investments and increase in international trade in aquatic animals and products. Early detection of emerg- ing diseases is considered key to their control, and knowledge about the existing disease is essential in developing national control or containment strategies or declaring disease freedom. Future planning needs to be inclusive to harness the strength of passive disease surveillance based on farmers' reporting and aim to build on the successes, lessons learned and capacity building achieved during the first phase of NSPAAD. The ground-level contact with fisheries inspectors, aqua-one centres, aquatic animal health laboratories or even chains maintained by feed companies can help in linking farmers to the NSPAAD collaborating centres, with an aim that no disease goes unreported. It is envisaged to strengthen capacity building of the State Fisheries Departments so that disease surveillance becomes an integral activity of these Departments and disease reporting is inclusive and credible. It also intends to strengthen the transport mechanisms of samples to diagnostic laboratories so as to arrive at accurate diagnosis. The NSPAAD collaborating centres and new aquatic animal health laboratories can be designated as state referral laboratories by the respective states and work in close linkage with State Nodal Officers for disease surveillance. A futuristic institionalized system cannot be sustainable with long-term gains unless it is equipped for past and future compatibility in terms of information, data and material. In the absence of such a dynamic system, the time-bound projects can end up as stand-alone programmes by losing the advantage which data enrichment can offer to support disease prediction modelling in future. To achieve this, an in-built system that can store all data and disease reports originating from any part of the country, track final diagnosis and husbandry conditions is the need of the hour. All units of data generation can be linked to a central informatics system, i.e. proposed Centre for Aquatic Animal Disease Informatics and Referral Diagnostics. This can be a central convergence point of all information related to disease cases on timescales, which will be a valuable resource in future for big-data analysis or even implementing artificial intelligence for developing disease prediction systems. Such a centre should have a reference designated repository of diseased samples as an integral part, to resolve any scientific ambiguity such as taxonomy or alterations in pathogen virulence, or trade-related conflicts on transboundary and emerging diseases.

The proposed surveillance programme will aim to establish a disease governance system for aquatic animal diseases in India, built-in linkages for effective reporting and detection in addition to providing evidence-based inputs to DoF, GoI for prevention and mitigation of aquatic animal diseases and address research issues when such need arises. Notably, under PMMSY, GoI, it is envisaged to strengthen the national surveillance programme with active involvement of stakeholders, especially States/UTs and research institutions. The disease surveillance programme would help in reducing losses due to diseases 
and thus doubling farmers' income. Besides, the surveillance on a national basis would inform DoF of the disease situation in the country, allow better targeting of efforts to control and reduce the risk of spread of aquatic animal diseases, provide early warning of disease emergencies, facilitate more specific contingency planning and strengthen international confidence on India's aquatic animal health status.

1. Rodgers, C. J., Mohan, C. V. and Peeler, E. J., The spread of pathogens through trade in aquatic animals and their products. Rev. Sci. Technol., 2011, 30, 241-256.

2. Dong, H. T., Ataguba, P., Khunrae, T., Rattanarojpong, T. and Serapin, S., Evidence of TiLV infection in tilapia hatcheries from 2012 to 2017 reveals probable global spread of the disease. Aquaculture, 2017, 479, 579-583.

3. MPEDA, State-wise details of shrimp and scampi production, 2019; https://www.mpeda.gov.in/MPEDA/year_wise.php\# (accessed on 13 September 2020)

4. The Economic Times, FY20 shrimp output may be a record, 2020; https://economictimes.indiatimes.com/markets/commodities/news/ fy20-shrimp-output-may-be-a-record/articleshow/73925714.cms (accessed on 13 September 2020).

5. DADF, Diagnostic Manual for Aquatic Animal Diseases of National Concern, National Bureau of Fish Genetic Resources, Lucknow, 2014, p. 118.

6. Sahoo, P. K. et al., Detection of goldfish haematopoietic necrosis herpes virus (Cyprinid herpesvirus-2) with multi-drug resistant Aeromonas hydrophila infection in goldfish: first evidence of any viral disease outbreak in ornamental freshwater aquaculture farms in India. Acta Trop., 2016, 161, 8-17.

7. Swaminathan, T. R. et al., Emergence of carp edema virus in cultured ornamental koi carp, Cyprinus carpio koi, in India. J. Gen. Virol., 2016, 97, 3392-3399.

8. Rajendran, K. V., Shivam, S., Praveena, P. E., Rajan, J. J. S., Kumar, T. S., Avunje, S. and Alavandi, S. V., Emergence of Ente- rocytozoon hepatopenaei (EHP) in farmed Penaeus (Litopenaeus) vannamei in India. Aquaculture, 2016, 454, 272-280.

9. Sahul Hameed, A. S., Abdul Majeed, S., Vimal, S., Madan, N., Rajkumar, T., Santhosh Kumar, S. and Sivakumar, S., Studies on the occurrence of infectious myonecrosis virus in pond-reared Litopenaeus vannamei (Boone, 1931) in India. J. Fish Dis., 2017, 40, 1823-1830.

10. Sood, N., Pradhan, P. K., Verma, D. K., Yadav, M. K., Ravindra, Dev, A. K., Swaminathan, T. R. and Sood, N. K., Candidatus Actinochlamydia pangasiae sp. nov. (Chlamydiales, Actinochlamydiaceae), a bacterium associated with epitheliocystis in Pangasianodon hypophthalmus. J. Fish Dis., 2017, 41, 281-290.

11. Behera, B. K. et al., Emergence of tilapia lake virus associated with mortalities of farmed Nile tilapia Oreochromis niloticus (Linnaeus 1758) in India. Aquaculture, 2017, 484, 168-174.

12. Girisha, S. K. et al., Red sea bream iridovirus disease (RSIVD) outbreak in Asian seabass (Lates calcarifer) cultured in open estuarine cages along the west coast of India: First report. Aquaculture, 2019, 520, 734712 .

ACKNOWLEDGEMENTS. We thank the Department of Fisheries, Ministry of Fisheries, Animal Husbandry and Dairying, Government of India for envisioning and financially supporting NSPAAD. We also thank the National Fisheries Development Board, Hyderabad for support; all the collaborating centres of NSPAAD for their contributions to this project, and Prof. Kenton L. Morgan (School of Veterinary Sciences, Liverpool, United Kingdom), Prof. C. V. Mohan (WorldFish, Malaysia), Prof. Indrani Karunasagar (NITTE University, Mangalore), Prof. Iddya Karunasagar (NITTE University, Mangalore), Dr A. G. Ponniah (Former Director, ICAR-NBFGR and ICAR-CIBA) and Dr Eduardo Leano for guidance.

Received 13 September 2020; revised accepted 1 November 2020

doi: $10.18520 /$ cs/v120/i2/273-277 